\title{
Aligning Textbook Affordability Efforts with State Performance Funding Metrics
}

\author{
Penny Beile \\ University of Central Florida, USA
}

\section{Introduction and Context}

It is likely that many, if not most, student-facing librarians have been asked whether the library carries their course textbook. Certainly, that has been the case at the University of Central Florida Libraries reference and circulation desks, where statistics indicate that over $10 \%$ of all reference questions the first two months of the semester are directly related to acquiring course materials. ${ }^{1}$ While it is conceivable that some students have the textbook and simply did not bring it with them to the library, it is also very possible that they do not have access to the readings because they have delayed or decided not to purchase the textbook. As reported by economist Barry Ritholz, textbook costs have almost doubled over the past twenty years, even controlling for a $55 \%$ inflation rate. ${ }^{2}$ Some commercial publishers have effectively priced textbooks out of the market for many students.

In 2016, the Florida Virtual Campus (FLVC) administered a statewide survey to Florida higher education students to examine how the cost of textbooks impacted their education, purchasing behaviors, and academic success. More than 22,000 students responded to the invitation to take the survey, and the FLVC ultimately reported that "the high cost of textbooks is forcing many Florida higher education students to make decisions that compromise their academic success." ${ }^{3}$ Disaggregated survey responses specific to the home institution, the University of Central Florida (UCF), were obtained and analyzed. Of the 1,975 UCF students who responded to the FLVC survey, $53 \%$ indicated that they "frequently" or "occasionally" had not purchased a textbook due to cost, and $19 \%$ attributed obtaining a poor course grade to not having the textbook.

Research suggests that students' lack of access to course materials from day one may place them at an academic disadvantage. ${ }^{4}$ This, in turn, has sparked a response from legislators, higher education associations, administrators, and, on the frontlines, course instructors and campus academic support units.

Federal legislation, specifically the 2008 Higher Education Opportunity Act, contains a section that requires institutions to communicate the price of course materials to students at the time of registration for the purpose of ensuring "that students have access to affordable course materials by decreasing costs to students and enhancing transparency and disclosure with respect to the selection, purchase, sale, and use of course materials." ${ }^{5}$ In 2015, the Affordable College Textbook Act (S.2176) acknowledged that the high cost of college textbooks was a barrier for many students in achieving a higher education and specifically called for expansion in the use of open textbooks to achieve savings for students. ${ }^{6}$ Just this year Congress funded a $\$ 5$ million grant to create open textbooks with the promise to continue funding next year. ${ }^{7}$

Complementing federal activity, over half of all US states have legislation that contains provisions for activity to reduce the cost of course materials for students. ${ }^{8}$ Within Florida, Statute 1004.085, Textbook and

Instructional Materials Affordability, ${ }^{9}$ explicitly authorizes institutional boards of trustees to adopt policies for the use of innovative pricing techniques and payment options for textbooks and instructional materials. Also, for the express purpose of allowing students time to shop for affordable options, each Florida system college and university must post a list of all required and recommended course materials at least 45 days prior to the first day of class for each term. A final requirement of the legislation includes an annual report submitted by boards of trustees to the respective chancellors of the college and university systems, highlighting cost variances, institutional initiatives designed to reduce the cost of textbooks, and courses that 
did not meet the 45-day posting deadline. These reports are then presented by the chancellors to the State Board of Education and the Board of Governors.

Accompanying Florida textbook affordability legislation is performance funding for state system universities. With the national trend moving away from funding institutions based solely on FTE student enrollments to aligning funding models with state goals and priorities, many of these incentives are based on performance indicators such as completion rates, time to degree, and number of degrees awarded in high-need areas, among others. In 2015, 32 states had been identified that had transitioned to performance funding with an additional five states in transition. ${ }^{10}$ It is likely the level of integration is higher now. Both Florida college and university systems have performance metrics, with university funding allocations based on performance on ten metrics. ${ }^{11}$

Of the ten metrics for Florida system universities, those most pertinent to textbook affordability efforts are Metric 3: Net tuition and fees per 120 credit hours, Metric 4: Four year graduation rate for full time FTIC, and Metric 5: Academic progress rate of second year retention with GPA above 2.0. ${ }^{12}$ Although not an outcome of adopting affordable textbooks, Metric 7: University access rate, or percent of undergraduates with a Pell Grant, is supported by access to no/low-cost course materials. A sub-metric of Metric 3, which addresses the cost of a college education, is access to affordable course materials. In 2014, UCF scored well on this metric compared to other FL system institutions, with the cost of attaining a college degree at a reported $\$ 21,060 .{ }^{13}$ By 2016 , this cost had increased to $\$ 24,190 .{ }^{14}$ Although still relatively low in comparison to other state system universities, the needle is moving up, which may result in a less favorable rating and a drop in the funding allocation, and this funding comprises a significant portion of the university operating budget.

The Florida performance funding model requires that state system universities contribute a portion of their institutional budget to be allocated based on performance. If the institution scores 51 or higher on the scale, their full institutional funding is restored. For fiscal year 2017-2018, the University of Central Florida scored 78 points ${ }^{15}$ and received their original investment of $\$ 40,062,707$ back, plus an additional $\$ 35,692,230$ in state investment funding, for a total allocation of $\$ 75,754,937 .{ }^{16}$ With millions of dollars in funding on the line, performance metrics in the state have serious implications for institutions. Consequently, administrators are exploring every option to maximize performance on the metrics, and student access to affordable course materials is of increasing interest across campus.

Performance funding metrics, along with metrics associated with the institution's bid for preeminence, ${ }^{17}$ both support and complement UCF's Collective Impact Strategic Plan (CISP). ${ }^{18}$ Each of the three drivers has metrics that are unique to each plan, as well as metrics that are shared across plans. Unique performance funding metrics range from number of students receiving Pell Grants (as an indicator of access), to median wages of students receiving a bachelor's degree, and on to the number of degrees awarded in identified areas of emphasis. ${ }^{19}$ Unique preeminence metrics include the number of National Academy members, institutional and research ranking at the national level, and entering student profiles (SAT and GPA). ${ }^{20}$ Unique CISP metrics seek to increase the number of faculty, graduate students, post-docs, patents, research funding, and diversity. ${ }^{21}$ The metrics that are shared across all three plans are most focused on student success and include first year retention rates, time to graduation, overall number of degrees awarded, and the cost to obtain a degree. Textbook affordability serenely resides at the intersection of the overlapping metrics of all three plans (see Figure 1) by directly reducing the cost to obtain a college degree and being positively correlated to higher student academic performance, including higher GPA, increased retention rates, and quicker time to graduation. ${ }^{22}$ Access to affordable textbooks also supports Pell Grant recipients and others with financial need. 
Fig 1. Relation of textbook affordability metrics to institutional goals

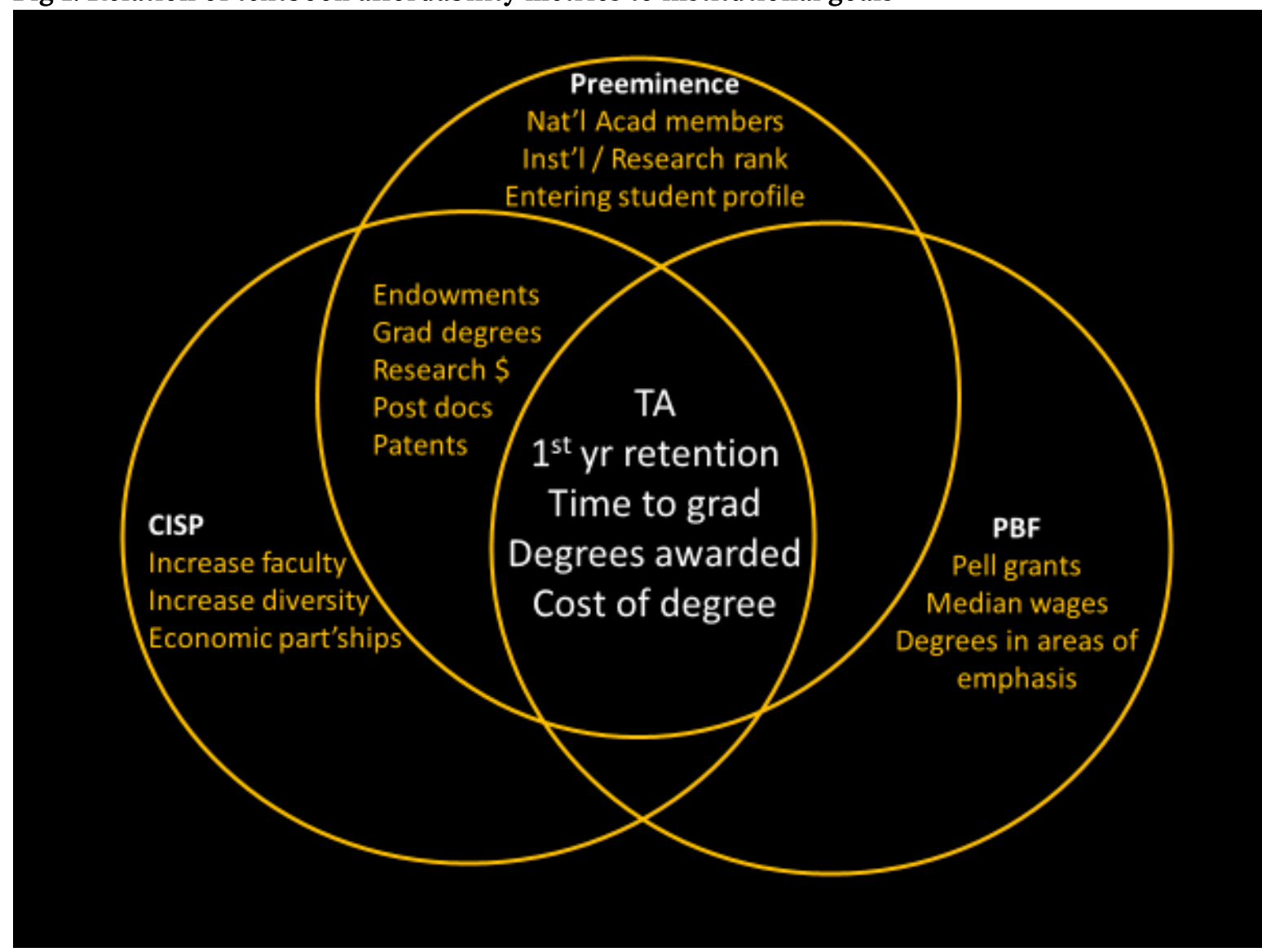

Textbook Affordability Model at UCF

This environment served as an impetus for librarians and instructional designers to form a small working group to promote and facilitate adoption of affordable textbooks. Beginning in summer 2016, and in collaboration with other campus partners, this grassroots effort has promoted affordable course materials and pursued three models to help faculty transition from commercially produced textbooks to no/low-cost alternatives. These models consist of adopting an existing open educational resource (OER); creating an OER using copyright compliant, openly accessible materials; and using library e-books as one-to-one replacements of the current textbook. Just this fall, a print textbook reserve collection was implemented, which adds a fourth model.

Faculty adoption of existing OER has been most successful at the GEP level, and OpenStax texts (http://openstax.org) are by far the most adopted. Our work with the faculty development center has been especially fruitful in reaching GEP-level instructors. The faculty development center offers programs which provide opportunities to offer textbook affordability sessions directly to faculty. These programs include week-long faculty development institutes and "Teaching and Learning Days," which are dedicated to a particular theme and only require a few hours of commitment. Another is a recent, large-scale initiative to "refresh" the GEP, which seeks to re-envision GEP courses into thematic strands, increase active learning, provide transparent assignments and consistent student learning outcomes across the GEP, and most importantly for textbook affordability, offer an opportunity to revisit course materials. Our work with the faculty center has led to several successful faculty adoptions of no/low-cost course materials in addition to invitations to present at faculty department meetings. The department meeting presentations, likewise, have resulted in opportunities to work directly with the teaching faculty. 
A second model, creating an OER using copyright compliant, openly accessible materials, has been the most labor-intensive and yet remains one of the most rewarding efforts to date. UCF Libraries employs a subject librarian model, whereby librarians are assigned to work with faculty and students in specific academic programs. Supporting this model are various professional positions that have functional roles. In this particular instance, a subject librarian in English recruited a faculty member teaching medieval literature to embark on a project to "break apart" his commercially produced anthology of medieval literature and pull together an openly accessible list of readings. Over the course of a semester this was accomplished with input from the instructor, who determined quality of readings and translations; the subject librarian, who looked for potential readings; the scholarly communication librarian and adjunct, who confirmed copyright or requested permission to use readings not in the public domain; and an instructional designer, who took low-quality PDF scans and reformatted them into line-numbered text. With 68,000 students and 2,000 faculty-and limited library staff and resources-it quickly became apparent that this type of project was not scalable at our institution.

The third model, using library e-books as one-to-one replacements of the current textbook, tends to support upper level and graduate courses. To date we have approached this model two ways; the first is running the university textbook list against library holdings and the second is through subject librarian promotion. Running the booklist first required obtaining it from the university bookstore, which involved submitting a request through the Higher Education Opportunity Act (HEOA). Once the booklist was received, the acquisitions librarian and an instructional designer devised a way to run it against library holdings. E-book candidates were further checked by ISBN, URL, user limits, and DRM.

The e-book candidates that made it to this round were matched against course data, including number of enrollments, course number, and instructor. We were initially excited to see that a potential savings of $\$ 800,000$ (calculation based on the new price of the textbook by number of student enrollments) could be realized if all faculty adopted all identified library-sourced e-books. Individual emails were sent to the instructors of the courses and their department chairs, with notes stating that the text was a one-to-one replacement, and included potential savings by course, the URL, sample text to put in the syllabus, and instructions on how to create a note in the faculty-facing textbook adoption platform.

Unfortunately, we failed to recognize that many textbooks now require an online access code and faculty were quick to point out that the online platforms were necessary to their teaching; this access was used by students to submit homework, take quizzes and tests, and in some instances, communicate with the instructor. One text that supported a differential equations course alone accounted for half of the projected possible savings but required a key code for online access. Ultimately, we tracked e-book adoptions that resulted in $\$ 37,000$ in student savings, generated goodwill with the faculty, and learned a valuable lesson.

Since that experience, we have been more successful in leveraging library collections to support textbook affordability through the efforts of subject librarians, who work one-on-one with their faculty. Several have sent suggested e-books to faculty, while others have taken all assigned textbooks in their programs and identified e-books for purchase that could be added to the collection. The process can be fairly timeconsuming on the front end, but only requires faculty to update their syllabi, which has translated to a high adoption rate. In the rare instances where faculty are reluctant to add the e-book to their syllabus or make a note in the faculty textbook adoption platform for students to come to class before purchasing materials, we have worked with an instructional designer colleague to send emails directly to students enrolled in these courses, alerting them to the library-sourced e-book option.

A final library initiative, implemented this fall, is the print textbook reserve collection. While faculty have always had the option to place their course materials on reserve (within allowances offered by Fair Use), the library consciously decided to purchase selected course textbooks for the 25 highest drop, fail, withdrawal (DFW) rate GEP courses, concentrating on those with the most expensive textbooks and the highest number of student enrollments. This collection supports over 13,000 students enrolled in 432 course sections, with 
initial funding of $\$ 10,000$ provided by the library. It is interesting to note that while the average cost of a new textbook at UCF is $\$ 79$, with a range of $\$ 0$ to $\$ 766$, the average cost of a textbook in the 25 high DFW courses is $\$ 178$, with a range from $\$ 12$ to $\$ 340$. It may also be of interest to note that we were able to purchase a total of 57 textbooks with the initial $\$ 10,000$ in funding support. Since implementation, the collection has enjoyed approximately 2,000 circulations. Certainly, if the number of circulations is any indication, the collection has been well received by students since its launch.

\section{Results}

Information related to affordable adoptions has been tracked since 2016, with faculty name and college, course information, year and semester of adoption, type of adoption, cost of the traditional text, and savings calculated as new cost of the old textbook by number of student enrollments collected. From spring 2016 through fall 2018, 122 unique faculty teaching 274 sections have reached 12,314 students, potentially saving them $\$ 1,050,172$ in textbook costs. Again, potential savings are calculated as the cost of a new course text by number of student enrollments. At every milestone the author has sent emails to campus stakeholders, including the vice president the library reports to, alerting them to our progress.

Some faculty have adopted open resources without facilitation by librarians or instructional designers, and much of the support provided to faculty who do require it is by instructional designers. These colleagues routinely rearrange open textbook chapters, embed in the learning management system, or help guide the creation of ancillary materials. Certainly, the textbook affordability initiative would not be as successful as it is without being able to rely on each other's respective strengths. But adoption of library-sourced e-books as one-to-one replacements of the existing course text and support of the 25 high DFW, high enrollment GEP courses through a print textbook reserve collection are contributions unique to the library. While we report total savings and celebrate decreasing the cost of course materials as a group, it is equally important to communicate the library's contribution, especially during times of scarce funding.

To that end, the library is quick to acknowledge the work of the instructional designers and other campus partners, while also describing our unique contributions to the initiative. In addition to overall savings, this entails reporting by type of adoption, and growth over time by type of adoption (see Figures 2 and 3). Overall, using library-sourced e-books has resulted in almost half of all savings tracked to date. Yet, a deeper look at savings by type of adoption over time reveals that the use of library e-books is gaining traction, outpacing use of open textbooks almost four to one in the fall 2018 semester. 
Figure 2. Savings by type of adoption: existing OER, library-sourced, or created OER

\section{Savings by type of adoption}

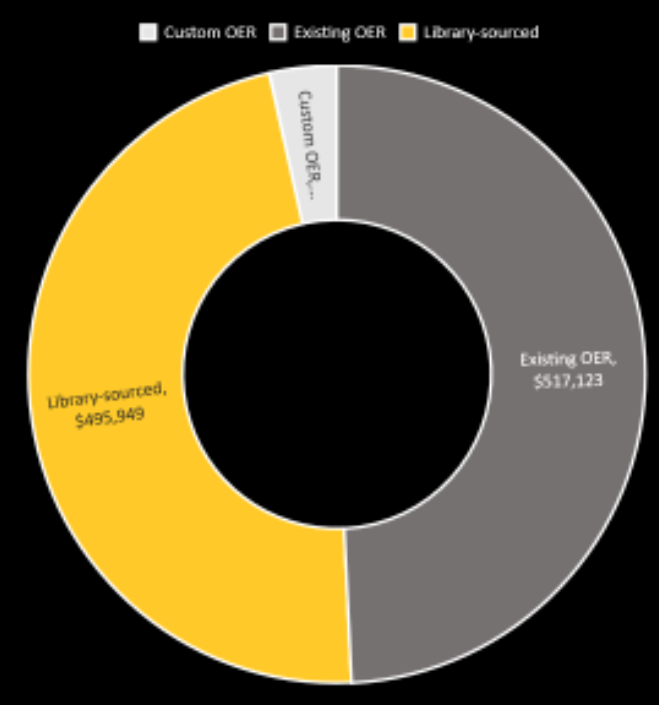




\section{Savings by semester and type of adoption}

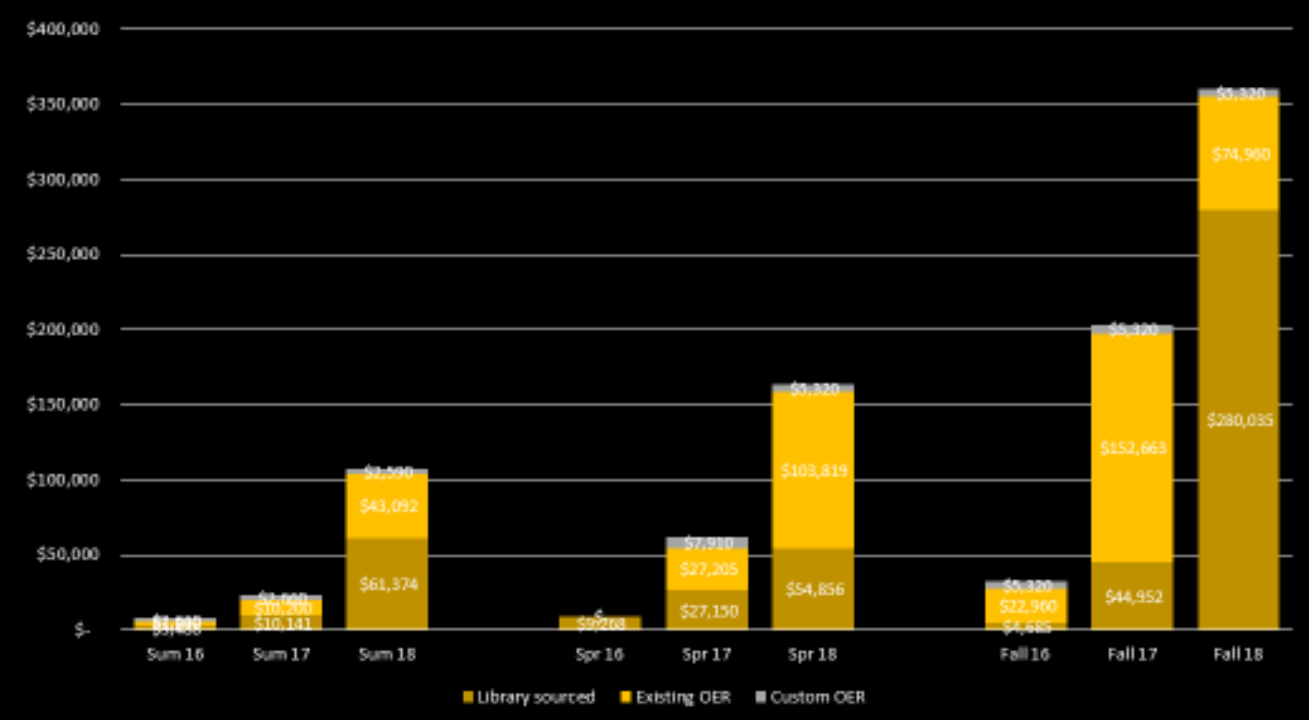

\section{Dissemination}

A significant amount of effort has been devoted to disseminating results of this initiative to institutional stakeholders, with audiences consisting of campus partners (such as the faculty development center, transfer student services, and advisors and other student academic support groups), faculty, student groups, and administrators. Outlets range from email blasts and digital signs to articles in institutional newsletters, on to direct presentations, meetings, and formal reports to university administrators. In every case, the message is customized based on audience interests and potential for support, collaboration, or other involvement.

Our message to campus partners is to let them know how textbook costs impact student academic outcomes, how we can collaborate, and to recruit support in the form of goodwill and partnerships. For example, communication with the faculty development center, which also works to support institutional goals, centers on student success metrics and opportunities to work directly with faculty who are revising courses or interested in improving their teaching or student learning outcomes. Similarly, we alerted academic advisors that the library was launching the print textbook reserve collection and invited them to the kickoff, which included refreshments and handouts. Shortly after, we presented to all GEP advisors on the topic, focusing on the cost of textbooks in the high DFW, high enrollment GEP courses and how to work with students to reduce their textbook costs. They were quite surprised to find that if a student enrolled in selected sections of microeconomics, chemistry, biology, and philosophy-all GEP courses-their textbooks would run right at $\$ 1,000$. With the cost of tuition and fees to attend UCF full time for two semesters at approximately $\$ 6,000$ and one semester costing approximately $\$ 3,000,{ }^{23}$ books for this course load can add an additional $33 \%$ to tuition and fees. 
With faculty, we hope to communicate the impact of high cost textbooks on student behaviors of delaying or not purchasing the text, how they can reduce the cost of course materials, and to recruit support in the form of no/low cost adoptions and testimonials. Presentations have been most effective, some offered at the faculty development center's workshops and institutes, as well as at faculty department meetings. Recent presentations to the Faculty Senate Steering and full Faculty Senate meetings resulted in the topic of textbook affordability being assigned to committee, with the endorsement of the Senate that institutional resources be allocated to provide necessary faculty training.

Needless to say, student groups have been exceptionally receptive, and our communication with them is to let them know that the library is a partner and is taking concrete measures to support their success, and to recruit support in the form of book drives and funding. As mentioned earlier, some students receive email blasts that alert them the library has their text as an e-book or see web banners about the print textbook reserve collection, but we have also presented to library student advisory boards and to the Student Government Association (SGA). The SGA presentation resulted in additional funding to expand the print textbook reserve collection. As such, the SGA is a partner, and their role will be acknowledged in any campus presentations, newsletter articles, and on digital signs.

And of course, information is sent to university administrators, with the goals of communicating the importance of textbook affordability in supporting student success, demonstrating how the library contributes to that effort, and recruiting support in the form of communication and additional resources. Initially, savings and activities were reported to pertinent vice provosts and vice presidents, as well as heads of various academic success units. It wasn't until a vice provost forwarded our email to the institutional effectiveness unit that we were invited to report savings for performance-based funding. Now, several meetings later, we have refined the process to collect additional needed data points and report metrics in support of the "cost of books and supplies." As mentioned earlier, the majority of states have moved to a performance-based funding model for higher education. If demonstrating the value of the library is of importance, library administrators would do well to scan the metrics and position their libraries to collect and report metrics most relevant to them.

Further, we have found that administrators respond quickly and positively when we directly connect the dots between the textbook affordability initiative and achieving institutional goals and metrics. Another best practice is to use locally collected data whenever possible. As noted before, large-scale research suggests that students who have access to no/low-cost course materials enjoy better academic outcomes and students in Florida who answered the FLVC survey say that textbook costs have impacted their academic behaviors. But it is much more meaningful to administrators to describe outcomes and behaviors of the students at the home institution.

In addition to obtaining institution-specific responses to the statewide survey, we have administered student surveys (led by our instructional designer colleagues) and conducted student focus groups. Institutional survey data and focus group comments corroborate national and state research reports, and also make the story more compelling. Of course, reporting results of larger scale studies is a valid strategy, but when the president hears that $83 \%$ of our students frequently or occasionally delay purchasing textbooks due to cost, it sends a more personal message that says, "These are our students, and our students are struggling to pay for course materials."

\section{Outcomes}

As noted in the previous section, campus partners were consciously recruited through dissemination of the textbook affordability project, with responses ranging from increased communication and interest from student advisors, to increased collaboration and awareness with faculty and students, on to access to faculty at workshops and through GEP refresh from the faculty development center. Metrics reporting to the institutional effectiveness unit, who compiles and submits reports for performance-based funding and 
preeminence, has led to a more robust relationship. Prior to textbook affordability, the library had received little traction in its request for assistance with a data dashboard of library interactions and key student success metrics. That project is now back on track; perhaps due to reporting of metrics, perhaps due to increased communication between the two entities.

Interest continues to grow at the broader institutional level and consequently, several other outcomes have been realized or are on the horizon. In addition to performance-based funding metrics, the associate vice provost for the division of Teaching and Learning is primarily responsible for textbook affordability reports to the board of governors and the state legislature. As such, she is working with the library to include textbook affordability advice and updates in her periodic newsletters to faculty, collaborating on a campuswide email to faculty acknowledging their efforts in this area, and discussing options for the division to host a unit-agnostic website dedicated to textbook affordability.

Similarly, the vice provost for digital learning, which includes the instructional design unit, has taken steps to formalize the relationship between the library, Digital Learning, and textbook affordability. The vice provost has allocated an impressive suite of resources to support this collaboration and identified four areas of strategic emphasis; including OER adoption, use of library-sourced course materials, partnering with other institutions to identify low-cost courses, and implementing a platform whereby large volume purchases result in reduced course materials costs. Corollary to these strategic areas is the need for forwardfacing communication, standardized metrics reporting, and a committee or advisory board comprised of campus stakeholders.

Given the library's staffing levels relative to an institution of over 68,000 students, perhaps the outcome with the greatest potential for impact is the new textbook affordability/student success librarian position, which recently was funded by the Student Success Investment Model (SSIM), an initiative out of the Provost's Office. The SSIM was founded by the provost for campus units that do not generate funding from teaching student credit hours, but who have potential to increase student success. Initially, members included such high-profile units like student development and advising, graduate studies, undergraduate studies, and the honors college. The vice president for information technologies, which includes the library, advocated for the library to hold membership on the committee and was successful after presenting data and study results indicating how the library supports student success. Subsequent to achieving membership, each unit submitted a request for funding, presented rationale for the request, and then debated merits of each proposal and voted on funding.

The library was able to present compelling evidence of its textbook affordability work, related results to performance-funding metrics, and demonstrated how a dedicated position could accelerate work in this area. This illustrates that the topic is of interest to high-level administrators and that they think it has the potential to positively impact student success, performance funding, and institutional goals. At the time of this writing, a successful search has been conducted and the new textbook affordability librarian will soon begin work.

Ostensibly, the primary purpose of this paper was to illustrate how the library tied textbook affordability efforts to performance-based funding, and that aspect of the initiative has been successful but also continues to mature. Other outcomes, some unforeseen, also have been realized. Among them are strengthening faculty relations through subject librarian collaboration, elevating the perception of the library with pertinent campus academic support partners, sending a strong message to administrators that the library plays a key role in student success, and providing a venue for the library to meet its primary mission of supporting excellence in teaching and learning.

What is more difficult to capture is the response of students who now have access to affordable course materials. One professor who replaced a $\$ 190$ astronomy textbook with an OpenStax version commented, "When I announced to my class of 200 students that they could freely access the textbook online, I received 
a standing ovation. I had no idea what it meant to them.” And while sending metrics for performance-based funding reports remains a key goal, student gratitude for reducing the cost of a college education-and thereby making higher education more accessible-may be the greatest motivator of all.

-Copyright 2019 Penny Beile

\section{Endnotes}

1. Richard Gause (librarian), discussion at internal meeting, University of Central Florida, January 14, 2019.

2. Barry Ritholz, "Price changes (Jan. 1997-Dec. 2017): Selected US Consumer Goods and Services, and Wages," accessed December 17, 2018, https://ritholtz.com/wpcontent/uploads/2018/02/pricechanges.png.

3. FLVC: Florida Virtual Campus, 2016 Student Textbook and Course Materials Survey: Results and Findings (Tallahassee, FL: 2016), p. 3 , http://www.openaccesstextbooks.org/pdf/2016_Florida_Student_Textbook_Survey.pdf.

4. Lane Fischer, John Hilton III, T. Jared Robinson, and David Wiley, "A Multi-institutional Study of the Impact of Open Textbook Adoption on the Learning Outcomes of Post-secondary Students," Journal of Computing in Higher Education 27, no. 3 (2015): 165-168, and Nicholas B. Colvard, C. Edward Watson, and Hyojin Park, "The Impact of Open Educational Resources on Various Student Success Metrics,"

International Journal of Teaching and Learning in Higher Education 30, no. 2 (2018): 267-271.

5. Higher Education Opportunity Act, Pub. L. No. 110-315, 122 Stat. 3078 (2008), Section 133, https://www.govinfo.gov/content/pkg/PLAW-110publ315/pdf/PLAW-110publ315.pdf.

6. Affordable College Textbook Act, S. 2176, 114th Cong. (2015), Section 2, https://www.congress.gov/bill/114th-congress/senate-bill/2176/text.

7. Nicole Allen, “Congress Renews \$5 Million Open Textbook Pilot for Second Year," SPARC, September 26, 2018, https://sparcopen.org/news/2018/open-textbooks-pilot-fy19/.

8. “OER State Policy Tracker," SPARC, accessed December 17, 2018, https://sparcopen.org/our-work/statepolicy-tracking/.

9. 2017 Florida Statutes, Textbook and Instructional Materials Affordability, Tallahassee, FL: Florida Senate, 2017, 1004.085, http://flsenate.gov/Laws/Statutes/2017/1004.085.

10. Kevin Dougherty and Rebecca Natow, The Politics of Performance Funding for Higher Education: Origins, Discontinuation, and Transformations (Baltimore: Johns Hopkins University Press, 2015).

11. Board of Governors of the State University System of Florida, "Board of Governors Performance Funding Model Overview," https://www.flbog.edu/board/office/budget/_doc/performance_funding/OverviewDoc-Performance-Funding-10-Metric-Model-Condensed-Version.pdf.

12. Board of Governors, "Performance Funding Model."

13. Board of Governors of the State University System of Florida, "Board of Governors Performance Funding Model 2014-2015," https://www.flbog.edu/board/office/budget/_doc/performance_funding/UniversitySlides_2014-15.pdf.

14. Board of Governors of the State University System of Florida, "Board of Governors Performance Funding Model 2016-2017," https://www.flbog.edu/board/office/budget/_doc/performance_funding/UniversitySlides_2016-17.pdf.

15. University of Central Florida Institutional Knowledge Management, "Performance Based Funding Metrics, 2017-2018," https://ikm.ucf.edu/files/2018/06/2017-18-UCF-PBF.pdf.

16. Board of Governors of the State University System of Florida, "Board of Governors Performance-Based Funding Allocation, 2017-2018," https://www.flbog.edu/board/office/budget/_doc/performance_funding/Allocation-Year-4-2017-18Revised-6_22_17.pdf.

17. Board of Governors of the State University System of Florida, "Path to Preeminence: Five-Year Benchmarking Plan University of Central Florida, July 2016," 
https://www.flbog.edu/documents_meetings/0201_1010_7588_7.5.2\%20SPC\%2004b\%20UCF\%205Year\%20Emerging\%20Preeminence\%20Plan.pdf.

18. University of Central Florida, "Creating our Collective Impacts: An Overview of our Promises and Strategies,” accessed January 14, 2019, https://www.ucf.edu/strategic-plan/files/2017/07/Creating-OurCollective-Impact-rev072017.pdf.

19. Board of Governors, "Performance Funding Model Overview."

20. Board of Governors, "Path to Preeminence."

21. UCF, "Collective Impact."

22. Fischer, Hilton III, Robinson, and Wiley, "A Multi-institutional Study," and Colvard, Watson, and Park, "The Impact of Open Educational Resources."

23. University of Central Florida, "School Costs 2018-2019," https://finaid.ucf.edu/applying/costs/\#1718. 